\title{
8 Informed consent and clinical trials
}

\section{A Jewish perspective}

\author{
David Heyd
}

Clinical trials started no more than 150 years ago. Informed consent is an even more recent moral principle in medical practice. Accordingly, it is no surprise that the Jewish tradition (like all other religious and ethical systems) consists of no direct instruction on these practices. However, it does not mean that the two-and-a-half millennia old corpus of Jewish law is completely silent on the principles which may guide us in modern times in the regulation of experiments on human subjects and the role of individual consent on the part of those participating in them.

It is a second-level methodological principle in the Jewish halakhic tradition that any practical opinion or ruling must be anchored in previous opinions of rabbinical authorities. These, in turn, also rely on earlier rulings and the argumentation supporting them-down to the formative texts of the Talmud and ultimately the Torah, the foundation of all religious authority. One of the most powerful intellectual tools for forming opinions on matters that are novel and never addressed in the past is called hekesh, which can be translated as analogy or inference. Analogical thinking is the bridge between the necessity of maintaining the binding authority of past thought and the need to solve entirely new problems which arise in our age.

Take a typical case for the way contemporary rabbis debate the issue of clinical trials and informed consent. They go back to the sixteenth-century authority, Rabbi David ben Zimra, who in one of his thousands of responses to various religious questions discusses the following imaginary case:

What if the ruler tells a Jew, "let me cut one of your non-vital body parts or I shall kill one of your fellow Jews"? Some say that the Jew must let his organ be cut [thereby saving the life of his friend] since the organ is not vital [like a leg or an eye]. ${ }^{1}$

The historical context of this question in the sixteenth century is the experience of such terrible dilemmas faced by members of a persecuted minority 
which is, sometimes, the victim of cruel bullying. Strikingly, it became a classical source for rabbinical debates about life-saving organ donation in recent decades and, although more abstractly, about vaccination and participation in clinical trials. ${ }^{2}$

Ben Zimra's opinion is unambiguous: letting the ruler cut part of one's body is supererogatory, a matter of charity (hassidut), that is to say-going beyond the call of duty or the requirement of the religious law (din). This is not a trivial ruling since what is at stake is a person's life, which in Jewish law and ethics is the greatest of all values justifying even the violation of the Sabbath or almost all religious commandments. Hence, exempting one from saving the life of another human being calls for special justification, which Ben Zimra is at pains to provide. One kind of reasoning is that the sacrifice of one's limb may cause profuse bleeding resulting in death (and then, there is no reason for me to sacrifice my life for another person's life which is not worth more than mine). Another, more principled, the argument is that organs are integral parts of one's life and hence cannot serve as instruments for either punishing a criminal or saving another person's life. The ultimate argument of ben Zimra is that "the way of the Torah is gentle and it is necessary that its judgements agree with reason and commonsense." Can it really be expected, asks ben Zimra, that a person would allow his eye to be taken or his hand or leg be cut to save the life of another? Hence, he concludes that it is entirely optional and supererogatory to save one's friend's life by sacrificing a non-vital organ, and he who can bring himself to do it should be blessed. However, adds ben Zimra, if the sacrifice of an organ risks the life of the donor, he should be considered a "foolish" or irrational man (hassid shoteh), rather than a virtuous person.

The historical circumstances have changed: no ruler nowadays poses a threat "let me cut your hand, or I will kill your friend." Now the threat is "get vaccinated, or some people in your community will die in an epidemic." But, the normative dilemma remains the same: must an individual make some physical sacrifice to save other people's lives in the community. ${ }^{3}$ On the one hand, the Jewish normative system is typically communitarian, guided by solidarity and mutual responsibility. The social commitment may sometimes make substantial demands on the individual. On the other hand, the individual has a strong duty of self-care. ${ }^{4}$ The Jewish halakhic tradition wavers between the commitment to the saving of life (often encapsulated in the verse "thou shall not stand idly by") $)^{5}$ and the recognition that an individual has a special and maybe prior commitment to his own life and bodily integrity. There is a whole set of rules regarding the prohibition of self-mutilation, and the rabbis discuss in detail the exceptions which usually have to do with the possible saving of another human life and especially of a family member. But as we shall see, taking part in a clinical trial may be 
considered self-harm that cannot be justified in terms of the direct utility to an identifiable relative. Ben Zimra takes the middle way in solving this tension: sacrificing a limb for the sake of saving the life of another person is at most an admirable act of pure altruism but never a duty.

Organ donations are closely analogous to these older non-medical dilemmas since they involve a direct life-saving sacrifice of one's limb. But, vaccinations and clinical trials raise similar tensions between the individual duty of self-care and the social commitment to public health, which is a public good. Some vaccinations and some clinical trials involve danger to one's life and health and hence face the same difficulty that besieged Jewish communities in the past had to deal with. There is, though, a significant difference between clinical trials and medical experiments: the former is a practice that aims at preventing concrete threats of infectious disease, which may cause direct harm to a high number of people in the actual community. Medical experiments aim at promoting chances of curing diseases of future people whom we do not know and who may not have even been born yet. In that respect, refusing to be vaccinated and taking a free ride on fellow citizens is unfair and consequently justifies legal enforcement of some form. Medical experiments have a more remote utility and hence nowadays are never forced. Taking part in them is supererogatory. ${ }^{6}$ An even more extreme view is presented by the philosopher Hans Jonas who argues that due to their health risks, we should prohibit even volunteers from taking part in dangerous medical experiments and allow only the researchers themselves to undergo the experimental procedure as a matter of professional responsibility or noblesse oblige. However, in today's methodologies, Jonas' restriction is unrealistic. We need a very large number of subjects for any clinical trial and hence the cooperation of sick patients and healthy people for a control group. So to what degree should society allow its members to be subject to health risks?

Here, we come to another principle that has guided the rabbis from ancient times - the degree of risk. Naturally, contemporary rabbis are more aware of the importance of probabilities, and their arguments about medical experimentation have become more sophisticated. One significant distinction is between the experimental treatment of a particular sick patient and clinical trials that recruit healthy people. ${ }^{7}$ Regarding the treatment of a particular sick person, there is a distinction between a patient whose life is in danger and a patient who suffers from a non-fatal illness. If the threat of death is real and the treatment has some reasonable chance of saving the patient's life, although some chance of shortening his life, he is permitted (though not obliged) to choose to take the risk of that experimental treatment. It is interesting to note that unlike the older tradition, which did not even raise the issue of the patient's consent and relied entirely on the doctor's judgement, 
in this contemporary opinion, the patient is asked whether he wishes to take the experimental medication and if "it is impossible to talk about it with the patient" the family should be consulted. Although patient consent was already implied in older opinions of the kind we have discussed earlier in the form of leaving a space of permission to people who choose to donate an organ to save the life of another, rabbis in modern rulings explicitly require consultation with and consent of the patient. Furthermore, this applies equally to patients who are not in life danger but are given a chance to recuperate or relieve pain by taking an experimental medication.

As for experiments involving healthy people, these raise again the tension between the duty of self-care and the duty to save the lives of others. Again, there is a distinction between cases in which the other is an actual person "standing in front of me" and an unidentified future person who might enjoy the benefits of the clinical trial. If the actual person has a good chance to be saved from death by my help (blood donation or organ donation) while the risk of death I incur is minimal, then I am allowed to undergo the experimental procedure. However, if those who stand to benefit are future unidentified people (as is the case in most clinical trials), it would be my duty to take part in them only if the harm they involve is minimal or non-existent. ${ }^{8}$ Experiments on human subjects which are risky and potentially harmful in more significant ways are prohibited, which means that the doctors are not allowed to conduct them, and individuals are barred from volunteering to take part in them. Even informed consent would not legitimize them. The rabbinical ruling here accords with the common bioethical belief that "statistical lives" are not as valuable as the life of actual people (a belief that is challenged by some philosophers who regard this belief as irrational and ethically unsound). ${ }^{9}$

A relatively rigid and "polarized" opinion is expressed by Immanuel Jakobovitz, former chief rabbi of the U.K. and the pioneer of Jewish bioethics in modern times. Jakobovitz argues that, on the one hand, if there is no risk or danger involved in the experiment, we have a positive duty to take part in it; on the other hand, if there is some risk or danger to our health, we are straightforwardly prohibited from partaking in the experiment. ${ }^{10}$ This is a conservative view that is not representative of current rabbinical thought. It leaves no room for volunteering since taking part in the clinical trial is either obligatory or prohibited.

A more restrictive opinion is offered by an important rabbinical authority of our age, R. Waldenberg. ${ }^{11}$ Taking part in medical experiments should be kept entirely voluntary even if the risk involved is minimal or considered non-existent. One can never know about hidden risks involved in experimentation, and one should also consider the possibility of the unpredicted psychological impact of the procedure on the subject. Furthermore, one can 
never guarantee that the experiment would yield the expected benefit to future people. In other words, the probability of some harm to the subject taking part in a medical trial is often higher than is commonly thought, and the probability of benefit to future patients too low to justify any social obligation to participate in medical experiments. In my phrasing, Waldenberg's idea is that our bodies cannot serve as instruments for promoting the health of other people.

Although the patient's consent to treatment has not been traditionally considered by the halakha as a condition for medical treatmentparticularly in life-and-death situations - donating organs or participating in altruistic clinical trials was either forbidden or left to the free choice of the individual. Note that this is a weak sense of consent. However, under the influence of the rigid condition of informed consent in modern bioethics, we see the rabbis following suit. In one recent response, we find a clear statement: "even if the results of clinical trials are important, it is impossible to force an individual [to take part in them] without his knowledge." It is the doctor's duty to explain to the patient that with his help, human lives can be saved and ask for his consent. It is an offence to experiment on patients without their knowledge and against their will, even if the intention is the hope to cure future patients. ${ }^{12}$

On a more philosophical level, one should note that despite adopting the general idea of informed consent, the Jewish way of thinking does not accept the principle of autonomy as the grounds for informed consent. Autonomy is a richer concept than consent. It implies a general view of human beings as masters of their lives, the source of value and moral duty. It is the key notion of the anthropocentric version of humanism. Jewish religious thinking does not consider the individual as sovereign over his own life, and even his body is not considered his property. The requirement of consent in medical treatment is based on the potential suffering and harm to the body and the duty of self-care rather than absolute control of human beings over their lives. Thus, informed consent is not a major principle in the doctor-patient relationship since it is a doctor's duty to heal and a parallel duty of the patient to be healed. Being cured is not a matter of choice or personal autonomy.

However, when it comes to taking part in clinical trials, in which other people are the beneficiaries, there is no such duty (to be healed), and the individual must be asked to express his genuine consent before being recruited. ${ }^{13}$ Or take experiments on minors. They are prohibited because children cannot give consent to a procedure that might cause them pain or undermine their health. But, according to some rabbinical authorities, such experiments are allowed if they do not involve any suffering or risks to the child. This opinion conflicts with the liberal principle of autonomy, requiring 
consent even when there is no risk or pain involved in the experimental procedure. Consider the well-known danger of giving too much information to the patient (in either medical treatment or the recruitment of subjects for a clinical trial): as research has shown, too much information may disrupt the rational deliberation of the patient giving the consent, thereby undermining his autonomy. How do we know when autonomy is undermined? For the Jewish approach, restricting the amount of information given to the subject does not pose a problem since it is sufficient for the doctor to be convinced that extra information might cause unnecessary anxiety and suffering to the patient. The liberal, autonomy-based approach requires that all potential participants in the trial be given the same amount of information. The Jewish, consent-based attitude allows for different amounts of information to different subjects based on their degree of anxiety.

We can now see why the general attitude of contemporary halakha is compatible with the principles of the Helsinki Convention although its theoretical basis is different from the liberal principles underlying that Convention. Consequently, the legal regulation of experimentation on human subjects in Israel does not encounter any obstacle on the part of religious circles or parties. The Helsinki Convention is accepted as the supreme guiding document in the ethics of experimentation, and a Helsinki committee in each research hospital is a statutory legal requirement. But again, this does not mean that religious authorities accept the practice in the liberal terms of rights, autonomy and informed consent. They instead appeal to the principles of the sanctity of life, the duty of self-care, social solidarity and the value of bodily integrity.

How do all these developments in religious discussion of clinical trials, vaccinations and informed consent affect the actual way in which the orthodox religious sectors behave regarding those practices? There is a lower rate of immunization in the ultra-orthodox sector of Israeli society, but the cause for that phenomenon is not easy to detect. Indeed, there were a few cases in which leading rabbis instructed their communities to avoid immunization, but this occurred on the occasion of some medical controversy about the effectiveness of particular immunization (which also led some non-religious sectors to refuse to immunize their children). There is some general suspicion from these communities regarding the State and the Ministry of Health instructions. This suspicion is not derived from any formal religious argument against the idea of immunization as such. Living in small and relatively isolated communities, this sector in the population may feel that the "herd effect" of most people getting immunized is sufficient to protect them from the disease without them taking the inoculation.

Furthermore, some immunizations are thought of as conveying a negative moral message, such as the inoculation against papillomavirus, preventing 
cervical cancer in young women. However, beyond these sociologically relevant explanations, I should emphasize that the leading religious authorities do not oppose immunization, and many of them strongly encourage their followers, including children, to take them. Some consider them and clinical trials even as "a holy war" against the threat of fatal illness, a war that calls for a universal draft.

The issue then is not informed consent. Nor is it a problem of dietary restrictions (kashrut). Ultra-orthodox people-even though they can understand informed consent forms and the terminology used in them-need the authority of the rabbis to get involved in practices that might create a religious problem. For them, taking part in clinical trials or an immunization program is a matter of legitimacy rather than autonomy. We could say that their consent is mediated through the rabbis. Hence, as a matter of state policy, the medical community must convey to the rabbinical authorities stateof-the-art information about effective and experimental treatments so that the rabbis can lend their authority to individuals who hesitate to opt for them. The small minority of ultra-orthodox communities in Israel (and abroad) is not a case of a vulnerable group, but rather that of a group that should be encouraged by its religious leaders to join a highly profitable health scheme that their leaders recognize to be so. Mediated consent is the most effective means of creating trust conditions, which is a key to the success of experimental and preventive programs, indeed, to medical practice in general.

\section{Notes}

1 R. David ben Zimra, Responsa, part 3, section 627. My translation. Responsa are the most common medium in the development of halakhic rulings. They are written replies by a rabbi or a Talmudic scholar to inquiries on any matter of Jewish law. They are usually collected in volumes authored by either the rabbi himself or later by his pupils. They serve as rulings for the community of that rabbi and as opinions to be considered by later scholars engaged in the same inquiry.

2 I first encountered this source in a seminar paper of a student of mine, Noam Shar'abi, on the subject of organ donations.

3 There is a famous Talmudic dilemma: should the enemy command the community to hand over one of its members to be killed or otherwise be all put to death-what should the community do? The received answer is that the community should avoid sacrificing one individual and be prepared to be completely wiped out. However, if the enemy identifies the wanted individual, he should be handed over. By way of analogy, one might argue that if a particular individual contracted a highly infectious disease, he could be removed from the city, even if that means that he will die. However, if one person should be arbitrarily selected to take part in some lethal medical experiment that might save the whole community, it would be strictly prohibited to force him to undergo that experiment (although as in the case of the wanted individual, he will anyway die with the whole group). See Jerusalem Talmud, Tractate Terumot, p. 47a. 
4 "For your own sake, therefore, be most careful" (Deuteronomy 4:15). This verse was given in later ages its current physical meaning, including the duty to be healed by getting medical treatment.

5 Leviticus 19:16. This strong commandment to save the life of another person is unambiguously asserted by Maimonides, in his Mishne Torah, "Rotzeach uShmirat Nefesh," chapter 1, section 14: "Whenever a person can save another person's life, but he fails to do so, he transgresses a negative commandment, as Leviticus 19:16 states: "Do not stand idly by while your brother's blood is at stake."

6 Nevertheless, despite the authority of ben Zimra on the matter, there are some contemporary rabbis who-being aware of the immediate threats of certain new epidemics (say, AIDS) - view medical experimentation as "a holy war" ("a war of duty"), in which, according to the Torah, everybody is under a duty to take part. This is a more dramatic way of giving clinical trials a religious value. See, for example, M.D. Wellner, "The Rights and Authority of the Physician," in Hatora ve'Hamedina [The Torah and the State], Vol. 8, ed. Shaul Yisraeli (Kfar Haroeh, 1956-7), 306-307, 312. [In Hebrew].

7 Avraham Sofer Avraham, Nishmat Avraham, part 3, section 349 (Jerusalem: A.S. Sofer, 1985). The author is not a religious authority but a religious physician writing on bioethical issues.

8 Avraham Sofer Avraham, "Experiments on Human Subject," Noam: An Annual for the Discussion of Halakhic Problems 17 (1964): 161-164. [In Hebrew] The view expressed here is slightly different from that expressed in his other book cited earlier.

9 In his handy Encyclopedia for Halakha and Medicine (Jerusalem: Schlesinger Institute, 1994), Avraham Steinberg quotes R. Shlomo Zalman Auerbach as ruling that one is under no duty to save the life of another even if it involves no risk; but one is permitted to do so. However, it is prohibited to take part in an experiment that is risky to one's life. But, adds the rabbi, it may be allowed if the person to be saved from death is "standing in front of us," i.e., an identifiable concrete individual desperate to be saved. Entry "Medical Experiments on Human Subjects" (Vol. 7), p. 490.

10 Immanuel Jakobovitz, Jewish Medical Ethics (New York: Bloch Publishing Company, 1975), 291-294. Although the book's first edition was published before the Helsinki Convention in 1964, the second edition was published quite a while after it but, in a way, ignores it.

11 R. Eliezer Waldenberg, Tzitz Eliezer [Responsa], 2nd ed., Vol. 13, section 101 (Jerusalem, 1985). Waldenberg (1915-2006) was one of the foremost authorities on religious medical ethics.

12 Moshe Sternbuch, Teshuvot ve'Hanhagot [response], part 1, section 895 (Jerusalem: Netivot ha'Torah ve'Hachesed, 1992).

13 Yechiel Michael Barilan, Jewish Bioethics (Cambridge: Cambridge University Press, 2014), 119-122. 